\title{
ELECTROCARDIOGRAPHIC STUDY OF TYPHOID MYOCARDITIS
}

\author{
BY \\ F. MAINZER \\ From the Department of Internal Medicine, The Jewish Hospital, Alexandria, Egypt
}

Received March 11, 1947

During the last century the conception of circulatory failure in the course of acute infectious diseases has been subjected to changes in several instances. Circulatory failure of every kind has, of course, a serious influence on the action of the heart itself, and for this reason in infectious diseases it was considered in those early days (1860-95) as heart failure, and the anatomical damage of the myocardium was much investigated, especially by French authors.

A revolution of this conception was brought about by the investigations of Romberg and Paessler (1899); they showed the paralytic effect of bacterial toxins on the vasomotor centre and considered circulatory failure in infectious diseases merely as a paralysis of the peripheral blood vessels, the heart failure being mainly due to the condition of shock from the infection. This interpretation has been widely accepted till our days.

Later it was shown that in a considerable number of infectious diseases electrocardiographic changes can be found. This fact could apparently be related to the previous findings of myocardial damage. Indeed anatomical damage to the heart muscle occurring in a number of infections, especially rheumatic fever, diphtheria, scarlet fever, variola, and more rarely in cerebrospinal fever and other diseases, as well as in typhoid fever which is discussed in this paper, has been described during the second half of the nineteenth century.

Electrocardiographic changes were found in acute infections such as rheumatic fever, diphtheria, pneumonia, scarlet fever, streptococcal sore throat, cerebrospinal fever, typhus, Malta fever, grippal infections, cholera, and epidemic parotitis.

Our own findings in a hundred typhoid cases will be described and discussed here.

\section{CARDIOGRAPHIC FINDINGS}

In Egypt typhoid fever is a common disease; in our department there were between 80 and 120 admissions a year. The findings in 254 tracings from 106 cases are reported here; they are to be divided in 3 groups.

Series I (1933-34) 39 cases. In these only one cardiogram was taken some days after the return of the body temperature to normal.

Series II (1940-41) 60 cases. In these several cardiograms were taken (3-7) during the fever period and after the return to normal temperature, a total of 205 tracings.

Series III (1933-34) 7 cases. These were cases treated with chinin-bismuth-iodide. For reasons to be discussed below they are put together in a separate series; there was only one tracing as in series $\mathrm{I}$.

The cardiograms were made with an amplifier electrocardiograph in the three limb leads and in lead IV F. During the period 1933-34 before the standardization of the præcordial leads we took lead IV F with inverted poles; in some cases of this period no præcordial lead was taken. Some technical difficulties arose from the need to take the tracings in 
the wards and the unco-operative attitude of stuporous typhoid patients: and during the war the recording paper was of a very unsatisfactory quality, resulting in poor tracings.

Most of the patients suffered from Eberthella infection, and some from infection with Salmonella paratyphi (Paratyphoid A) or Salmonella Schottmuelleri (Paratyphoid B). The diagnosis was clinically certain in all cases and was confirmed by laboratory findings in all but two. Patients with a history or clinical signs of previous heart disease were not included in this report. Table I shows the laboratory findings.

TABLE I

LabORATORY Findings in Typhoid Cases

\begin{tabular}{|c|c|c|c|c|c|c|}
\hline \multicolumn{2}{|c|}{ Diagnostic procedure } & $\begin{array}{c}\text { Eberthella } \\
\text { typhosa (T) }\end{array}$ & $\begin{array}{c}\text { Salmonella } \\
\text { paratyphi (A) }\end{array}$ & $\begin{array}{c}\text { Salmonella } \\
\text { Schott- } \\
\text { muelleri (B) }\end{array}$ & $\begin{array}{c}\text { Mixed } \\
\text { infection } \\
T+B\end{array}$ & Totals \\
\hline $\begin{array}{l}\text { Blood culture } \\
\text { Stool culture } \\
\text { Agglutination }\end{array}$ & $\begin{array}{ll}. & . \\
. & . \\
. & .\end{array}$ & $\begin{array}{r}6 \\
49 \\
27\end{array}$ & $\begin{array}{r}-1 \\
2\end{array}$ & $\begin{array}{r}\overline{4} \\
13\end{array}$ & $\frac{-}{2}$ & $\begin{array}{r}6 \\
56 \\
42\end{array}$ \\
\hline Totals & . & 82 & 3 & 17 & 2 & 104 \\
\hline \multicolumn{2}{|c|}{ Clinical diagnosis only } & & & & & 2 \\
\hline & & & & & & 106 \\
\hline
\end{tabular}

If the blood-culture had a negative result, a frequent happening since the patients were admitted to the hospital at too late a stage of the disease, a stool-culture was done and repeated, if necessary; in cases with negative blood- and stool-cultures the agglutination test was made to confirm the diagnosis; consequently all patients registered in Table I as positive stool-culture had a negative blood-culture, and all registered as positive agglutination test had negative blood- and stool-cultures.

Of the 106 patients 7 died in the course of the infection. The causes of death were toxic circulatory failure in 2 cases ( 1 with acute nephrosis); intestinal perforation in 2 cases; and typhoid myocarditis in 3 cases.

The clinical picture of heart failure in typhoid myocarditis is very different from heart failure in valvular disease in its quick development, and resembles myocarditis in diphtheria in the combination of "forward failure" and "backward failure"; so in serious cases the extreme weakness and apathy, the moist and cold lividness of the skin with low blood pressure and insufficient pulse pressure of the "forward failure" is combined with engorgement and tenderness of the liver, congestion of the lungs, cyanosis, and sacral œdema; the heart sounds are dull and often a systolic murmur is present at the apex; there is always tachycardia, often embryocardia, and sometimes gallop rhythm at the apex.

The less conspicuous the symptoms are in slight cases, the more they fuse with the phenomena of the peripheral circulatory failure at the acme of the fever, and so the more important becomes the cardiogram for the diagnosis.

First we shall describe these findings and afterwards discuss their interpretation. Table II summarizes the frequency of electrocardiographic alterations in our observations.

Changes observed only in leads III and IV F were neglected owing to the dependence of their shape on the position of the diaphragm; so every registered abnormality was present at least in one of the leads I and II.

Columns B and C of Table II include patients with tachycardia or bradycardia only without other findings; since these changes occurred mostly combined with other cardiographic abnormalities, it does not represent the total number with tachycardia or bradycardia. 
TABLE II

Frequency of Electrocardiographic Changes in Typhoid Fever

\begin{tabular}{|c|c|c|c|c|c|c|c|c|c|c|c|}
\hline$\underset{\text { Normal }}{A}$ & & $\begin{array}{c}\text { B } \\
\text { Tachy- } \\
\text { cardia } \\
\text { only } \\
\text { ver 110) }\end{array}$ & & $\begin{array}{l}\text { C } \\
\text { Brady- } \\
\text { cardia } \\
\text { only } \\
\text { nder } 60 \text { ) }\end{array}$ & $\stackrel{\mathbf{D}}{\mathrm{A}+\mathbf{B}+\mathbf{C}}$ & $\underset{\substack{\text { Slight } \\
\text { abnormali- } \\
\text { ties }}}{E}$ & $\begin{array}{c}F \\
\text { Moderate } \\
\begin{array}{c}\text { abnormali- } \\
\text { ties }\end{array}\end{array}$ & $\begin{array}{c}\mathbf{G} \\
\text { Severe } \\
\begin{array}{c}\text { abnormali- } \\
\text { ties }\end{array}\end{array}$ & & $\stackrel{\mathbf{H}}{\mathrm{E}+\mathbf{F}+\mathbf{G}}$ & Total \\
\hline \multicolumn{12}{|c|}{ Series I: Electrocardiograms after disappearance of fever } \\
\hline 20 & 1 & 8 & 1 & 2 & 130 & 13 & 16 & $1 \quad-$ & 1 & 9 & 39 \\
\hline \multicolumn{12}{|c|}{ Series II: Electrocardiograms during and after the fever } \\
\hline 22 & 1 & 1 & 1. & 2 & $1 \quad 25$ & $1 \quad 10$ & 19 & 16 & 1 & 35 & 60 \\
\hline \multicolumn{12}{|c|}{ Series III: Electrocardiograms of patients treated with chinin-bismuth-iodide } \\
\hline 1 & I & - & 1 & - & $1, \quad 1$ & $1-$ & $1 \quad-$ & 16 & 1 & 6 & 7 \\
\hline 43 & 1 & 9 & 1 & 4 & 56 & $\begin{array}{c}\text { Total: } \\
13\end{array}$ & 25 & 12 & 1 & 60 & 106 \\
\hline
\end{tabular}

"Slight " cardiographic alterations included moderate decrease of voltage of the ventricular and final complex, if present in several leads. Of course the classification of "slight," "moderate," and "severe" is somewhat arbitrary, but does not prejudice the conclusions to be drawn.

Table II shows cardiographic changes in a little less than two-thirds of the examined cases, if the tracings were taken during and after the fever period (series II); such changes were present in less̄ than half, if tracings were taken only in the convalescent period; this result agrees with Table III showing that these changes persist only in half of the cases after the end of the fever period.

Special discussion is needed for the 7 patients treated with chinin-bismuth-iodide (series III). Here intramuscular injections of chinin-bismuth-iodide in oily suspension were made twice a week, 2-3 ml. according to the age ( $=0.05-0.075 \mathrm{~g}$. metallic bismuth), a total of 6-8 injections in every case. These patients with one exception developed serious circulatory failure in the course of the typhoid infection; the only exception was a mild case that received only 3 injections. All the 7 presented during convalescence severe cardiographic alterations indicating myocardial damage. We abstain from deciding if there was a causal relation between this treatment and the constancy of heart muscle involvement.

Changes of the final complex were the most frequent abnormality; $T$ was flattened, absent, or negative in two or more leads (changes present alone in leads III and IV. F were not considered). Often the S-T segment was below or above the zero-line. The ventricular complex often showed low voltage with slurring or notching. Right or left axis deviation was not infrequent: in several instances we noted a high voltage $Q$ in two leads (leads I and II or leads II and III). Mostly these cardiographic changes occurred together and combined with tachycardia or bradycardia, the latter in young patients with pronounced or sometimes extreme respiratory arrhythmia; there were curves resembling digitalis tracings by the combination of a slow pulse rate (with respiratory arrhythmia) with inverted $\mathbf{T}$ waves. A prolonged $\mathbf{P}-\mathbf{R}$ interval, described elsewhere as a frequent happening in typhoid fever (Porter and Bloom, 1935) was present in one instance only and was not permanent.

In earlier papers the frequency of the different cardiographic alterations is mostly registered by tables. Here in view of the great number we prefer to reproduce the curves of a few illustrative cases.

Case 1. A man, aged 21, with an unimportant previous history was admitted after a six days' fever on 11/4/40 with a temperature of $40^{\circ} \mathrm{C}$. (rectal). The pulse rate was 96 a minute. The heart was slightly enlarged to the left, with a systolic murmur at the apex. The spleen was palpable. Moderate anæmia existed: hæmoglobin, 65 per cent (10.4 g.); erythrocytes, 3,900,000; and leucocytes, 
7000. In the urine there were traces of albumin; tests for urobilin and urobilinogen were positive. The blood-culture was positive for Eberthella typhosa, the agglutination test 1:150. The fever fell after one week to between $38^{\circ} \mathrm{C}$. and $39^{\circ} \mathrm{C}$. and after three weeks to below $38^{\circ} \mathrm{C}$. The heart enlargement to the left increased. The liver became congested and tender. With temperatures about $37 \cdot 5^{\circ} \mathrm{C}$. the circulatory failure increased, the pressure decreasing from $130 / 55$ to $95 / 75 \mathrm{~mm}$. Neither strophanthine given intravenously nor vasomotor stimulants (caffeine, coramine) nor cortico-suprarenal hormone (percorten) could stop the failure. Death occurred after a 57 days' illness with the signs and the symptoms mentioned above.

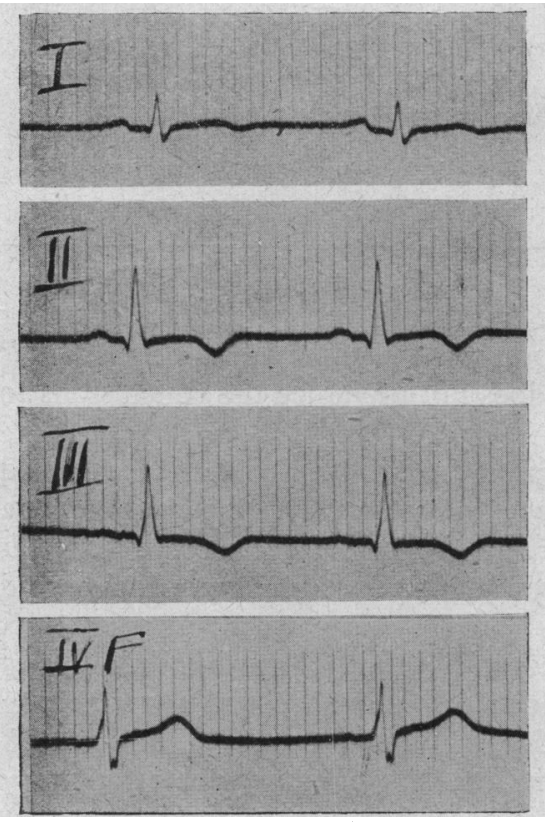

A

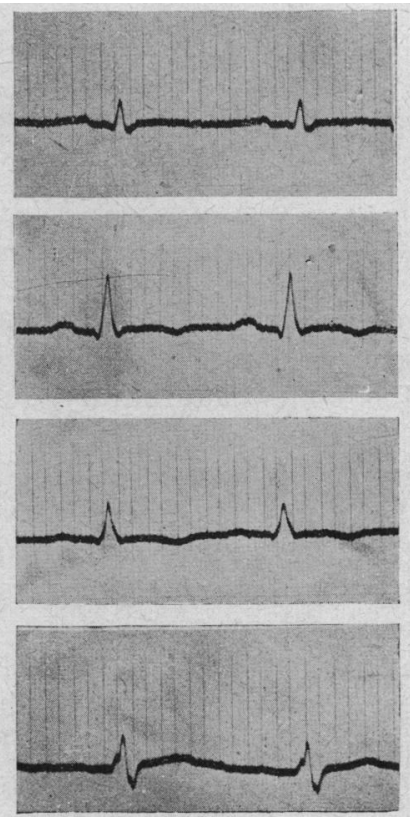

B

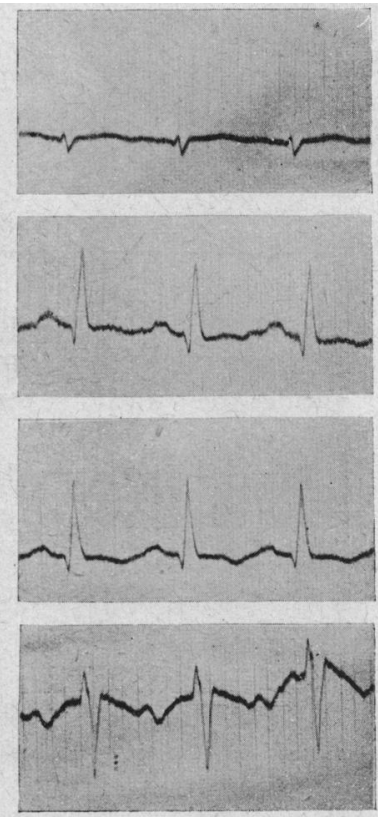

C

FIG. 1.-Electrocardiograms of a case of typhoid myocarditis with fatal issue.

Date Body temperature Pulse rate P-R R-S R-T

\begin{tabular}{lrrrrrr} 
& & & & \multicolumn{3}{c}{ (in seconds) } \\
(A) & $19 / 4 / 40$ & $38.7^{\circ} \mathrm{C}$ & 76 & 0.12 & 0.08 & 0.35 \\
(B) & $5 / 5 / 40$ & $38.5^{\circ}$ C. & 107 & 0.16 & 0.07 & 0.33 \\
(C) & $30 / 5 / 40$ & $37.6^{\circ} \mathrm{C}$. & 156 & 0.13 & 0.07 & 0.23
\end{tabular}

In Fig. 1A, T is negative in the three limb leads, and deeply in leads II and III. In Fig. 1B, 24 days later, with the increasing pulse rate the voltage of the ventricular complex and of the final wave has diminished; so the T waves are now nearly flat. Fig. 1C, two days before death, shows also a further increase in the pulse rate and the appearance of a $Q$ wave in leads II and III and diminished voltage of R-T. Changes of the lead IV E are not considered in view of the difficulty of replacing the chestelectrode always at the same spot and the influence of the variable position of the diaphragm.

Case 2. A seaman, aged 31, with an unimportant previous history was admitted to the hospital after a six days' fever on 25/7/40 with the typical picture of typhoid fever. There was a rose rash on the skin of the abdomen. The spleen was enlarged. Blood: hæmoglobin, 102 per cent $(=16.4 \mathrm{~g}$.$) ;$ erythrocytes, 5,200,000; leucocytes, 5700. The blood-culture was positive for Eberthella typhosa. After one week with a temperature between $39^{\circ} \mathrm{C}$. and $40^{\circ} \mathrm{C}$. it became subfebrile within the range of $37.5^{\circ} \mathrm{C}$. by lysis. Convalescence was uneventful and the patient was discharged on $8 / 11 / 40$. In the beginning of the disease the heart sounds were very dull, other peculiarities of the circulatory system were not present. Of the series of six curves we have chosen four for reproduction; only the first tracing had been taken during the fever period, the other three during convalescence. 


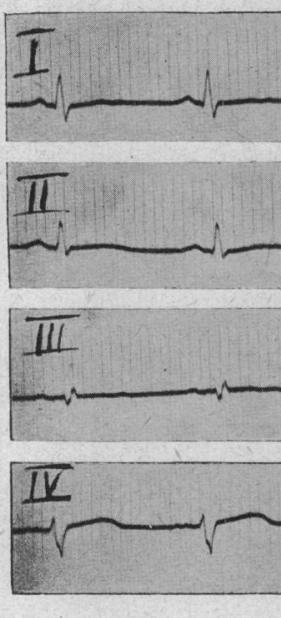

A

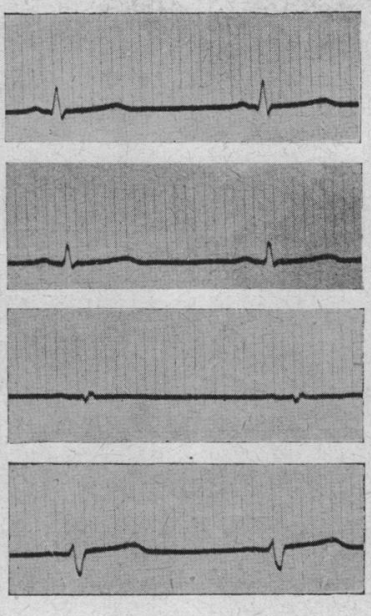

B

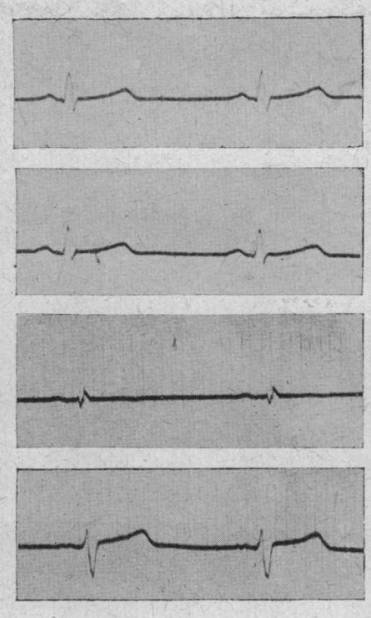

C

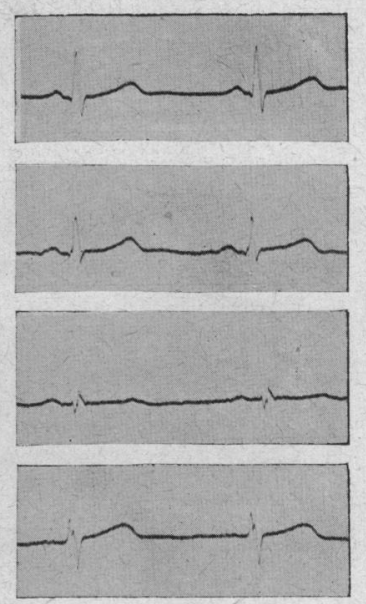

D

FIG. 2.-Electrocardiograms of a case of clinically latent typhoid myocarditis with cure. (Reduced to three-fifths.)

Date Body temperature Pulse rate P-R R-S R-T

$\begin{array}{lrlllll}\text { (A) } & 3 / 8 / 40 & 38 \cdot 5^{\circ} \mathrm{C} . & 75 & 0.13 & \text { (in seconds) } \\ \text { (B) } & 12 / 8 / 40 & 37 \cdot 1^{\circ} \mathrm{C} . & 65 & 0.12 & 0.08 & 0.35 \\ \text { (C) } & 21 / 8 / 40 & 36.9^{\circ} \mathrm{C} . & 63 & 0.15 & 0.07 & 0.38 \\ \text { (D) } & 31 / 8 / 40 & 36.9^{\circ} \mathrm{C} . & 70 & 0.17 & 0.08 & 0.37\end{array}$

In Fig. 2A, there is a notable flattening of the $\mathrm{T}$ wave, which in all leads is only just present; there is also a moderate decrease of voltage of the ventricular complex compared with later tracings. The changes disappeared slowly and step by step. The bradycardia, very pronounced in the beginning, disappeared likewise gradually.

Case 3. A girl, aged 18, with unimportant previous history was admitted to the hospital after a five days' fever (on 15/11/33) with the clinical picture of an exceptionally serious typhoid fever.

The blood-culture was positive for Eberthella typhosa. Blood: hæmoglobin, 52 per cent $(8 \cdot 3 \mathrm{~g}$.), erythrocytes, $3,000,000$; leucocytes, 6000 . The course of the disease was likewise very serious. The fever between $39^{\circ} \mathrm{C}$. and $40^{\circ} \mathrm{C}$. lasted during two months including two relapses of short duration. After a week's stay at hospital a slight intestinal hæmorrhage occurred. Without peculiarities of the heart itself the circulation was in a critical condition from the beginning for six weeks. At the time of discharge, tachycardia persisted with a pulse rate about 150 after slight exertion. There were three electrocardiograms without præcordial leads (1933).

In Fig. 3A, the $T$ waves are negative in all three limb leads; the $\mathrm{S}-\mathrm{T}$ segment is below the zero-line in leads I and II. The A-V conduction time is conspicuously prolonged with $P-R$ of $0.23 \mathrm{sec}$. After a fortnight convalescence with normal temperatures (Fig. 3B) the cardiographic changes had disappeared only partially, the final complex in lead II being abnormal; after a further month (Fig. 3C) the tracing was normal in spite of the clinical instability of the circulation.

Case 4. A girl, aged 12, was admitted to the hospital on 4/12/34 with a fever of three weeks' duration. For one week the fever had ranged between $39^{\circ}-40^{\circ} \mathrm{C}$., but previously there had been subfebrile temperatures. Before the admission to the hospital a blood-culture was positive for

- Salmonella Schottmuelleri (Paratyphosus B). The course of the disease was uneventful with a month of fever between $39^{\circ}$ and $40^{\circ} \mathrm{C}$. During the fever period relative bradycardia existed with pulse rates about 100; in convalescence it rose to 120 and after slight exertion to $140-160$ and remained so during three months. During the first 3 weeks after admission the patient received twice a week intramuscular injections of chinin-bismuth-iodide in oily suspension $(0.05 \mathrm{~g}$. bismuth per injection). The tracing taken on the fifth day without fever shows notable changes of the final complex. $T$ is negative in the limb leads and the S-T segment in leads II and III is below the zero-line and fused with the initial branch of $\mathrm{T}$. 

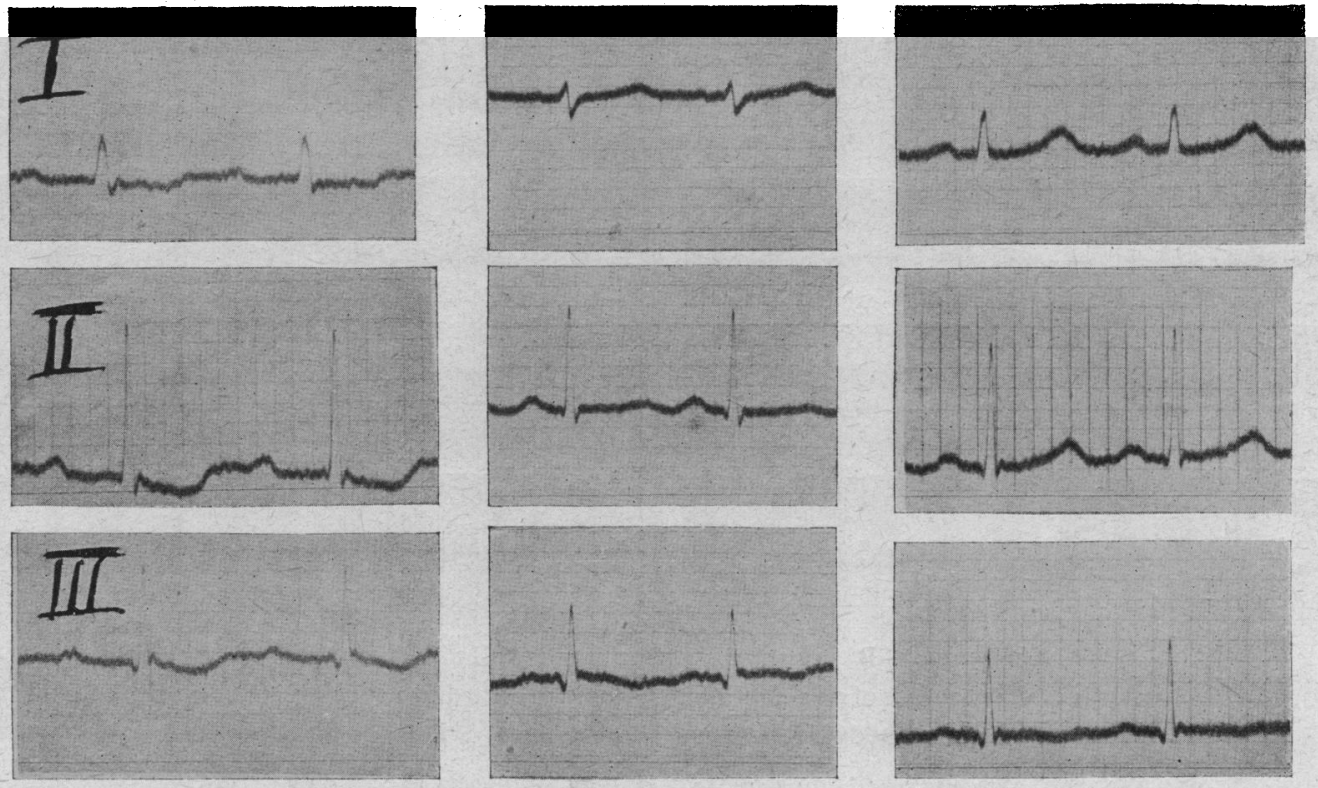

A

B

C

Fig. 3.-Electrocardiograms of a cured case of typhoid myocarditis with temporarily prolonged A-V conduction.

Date Body temperature Pulse rate P-R R-S R-T

$\begin{array}{lrllllll}\text { (A) } & 9 / 10 / 33 & 38.7^{\circ} \mathrm{C} & & 110 & 0.23 & \text { (in seconds) } \\ \text { (B) } & 8 / 11 / 33 & 37.1^{\circ} \text { C. } & -144 & 0.13 & 0.06 & 0.35 \\ \text { (C) } & 18 / 12 / 33 & 37.0^{\circ} \mathrm{C} & & 134 & 0.05 & 0.05 & 0.28\end{array}$

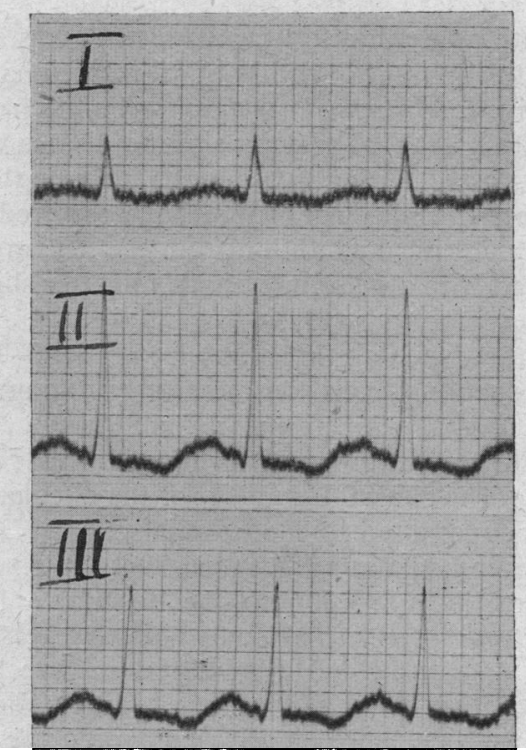

Fig. 4.-Electrocardiogram of a case of typhoid myocarditis in a patient treated with chinin-bismuth-iodide (taken after convalescence).

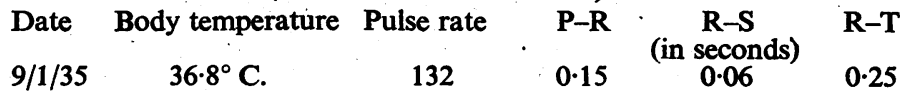


The time relation between the cardiographic changes and the infectious fever is not only interesting from the pathological point of view, but is also important for the interpretation of the tracings. The question is, if there is any parallelism between the fever as a measure of the infectious process and the development of cardiographic abnormalities. For this purpose we must examine (1) which is the phase of the infection giving rise to the cardiographic alterations, and (2) whether the changes disappear during the fever or persist after the fever with normal temperatures. Series II of Table II is a satisfactory basis for this examination. Out of the 35 patients in column $\mathrm{H}, 12$ are not considered because of the insufficient number of tracings; this includes 5 fatal cases, 3 of them dying from typhoid myocarditis. In the remaining 23 , the abnormal tracings persisted in 18 cases during convalescence; their disappearance lasted mostly from one to three weeks, in some instances even more. Abnormalities persisting indefinitely were not observed. But tachycardia between 120 and 140, especially after slight exertion, was often present many weeks after the recording of otherwise normal tracings. In three cases the changes disappeared during the fever period. In one case there was a complete correlation between the fever and the intensity of the cardiographic changes. In another case they developed only after that the infection lasted, with normal temperatures.

\section{COMMENT}

Electrocardiographic abnormalities in typhoid fever, although in a restricted number of observations, were described by several investigators (Bowe, 1929; Chagras, 1931; Master, Romanoff, and Jaffé, 1931; Lessard, 1933; Porter and Bloom, 1935; and Kiss and Wolleck, 1935). It is known that fever by itself, physically induced, can produce electrocardiographic changes (Vesell and Bierman, 1936; Knies, 1941; Clagett, 1944): these abnormalities, however, are slight.

In typhoid fever anatomical damage of the myocardium is regularly present: as early as in the second half of the last century this fact has been observed by several investigators (Hayem, 1869; Landouzy and Siredey, 1887; Romberg, 1893); cloudy swelling or hyaline degeneration of the myocardial fibres with necrotic foci of microscopic size and infiltration of the heart muscle, interstitial or focal, may be found.

In typhoid fever a shock-like peripheral circulatory collapse exists; in shock, as is well known, cardiographic changes similar to those in coronary insufficiency can occur (Scherf and Klotz, 1944). In our observations, however, the changes persisted longer than the fever and disappeared only slowly during convalescence; in one case they developed even after recovery from the fever. In view of these time relations a causal connection between the peripheral circulatory disturbances and the cardiographic changes cannot be assumed (even if at the acme of the infection the peripheral failure can contribute temporarily to their development).

Vagal stimulation might be a factor in producing changes of the final complex with reference to their combined occurrence with bradycardia (and respiratory arrhythmia); however, the same alterations were found, and even more frequently, associated with tachycardia.

Severe anæmia can also alter the cardiogram (Baugé, 1933; Bloch, 1937; and Szekely, 1940); in our cases severe anæmia was only exceptionally present, and jaundice (Meier, 1940) was seen in only one instance.

In typhoid fever as well as in other infections, anatomical damage of the suprarenal glands is a common finding (Dietrich, 1918; and Dietrich and Siegmund, 1936), and cortical failure has been supposed to be a factor in the development of the circulatory shock: the curves of the Addisonian crisis, however, are very different from those in typhoid fever or in other infections (Delius and Opitz, 1935; and Goodof and Macbryde, 1944); they are characterized by tall, narrow, upright $\mathrm{T}$ waves. 
Finally B-avitaminosis could be suspected as a factor intervening in the development of typhoid cardiograms, produced by lack of thiamin (Weiss and Wilkins, 1937; Dustin, Weyler, and Roberts, 1939; and Schott, 1944), or of niacin (Feil, 1936; and Mainzer and Krause, 1940). For a long period medical science recommended diets for typhoid fever that were essentially hunger diets; furthermore, it is often difficult to feed these patients sufficiently. In our department a high-calorie diet with vitamin preparations was customary; vitamin deficiency could have occurred only exceptionally.

So the cardiographic alterations in typhoid fever can be referred to the anatomical damage of the myocardium produced by the infection; the tracing is the expressicn of the typhoid myocarditis.

The myocarditis is the cause of death more often than the diagnosis is made. It is easily overshadowed at the acme of the infection by the peripheral circulatory disturbance; the clinical manifestations of this myocarditis, tachycardia and circulatory instability after exercise, only become manifest in convalescence and persist for a longer time in most cases than the cardiographic alterations.

\section{SUMMARY}

The electrocardiographic findings of 106 cases of typhoid fever are described. In 35 of 60 patients cardiographic abnormalities (other than tachycardia or bradycardia with or without respiratory arrhythmia) were encountered during the infection; in 18 they persisted during convalescence; in 1 they developed only in this period. In 12 cases the time relation between the infection and the development of the cardiographic changes could not be observed for technical reasons (lack of a sufficient number of tracings, death during the infection, etc.).

The cardiographic abnormalities take mostly between one and three weeks to disappear (after the onset of the convalescence). Clinical phenomena indicating an instability of the circulatory system (tachycardia) frequently persist for a long time ( 1 to 3 months) after the disappearance of the cardiographic changes.

Out of a series of 106 patients the cardiograms taken during convalescence were abnormal in 60 instances. Deformations of the final complex were most frequently observed: flat or negative $T$ waves and displacement of the $S-T$ segment. Appearance of abnormal $Q$ waves, development of left or right axis deviation, decrease in voltage, slurring or notching of the ventricular complex were also common findings. In one case a temporarily prolonged A-V conduction was present.

By excluding the possible influences of other factors on the cardiogram (fever, peripheral circulatory failure, suprarenal insufficiency, jaundice, B-avitaminosis) it is shown that the abnormal tracings can be referred to the anatomical damage of the myocardium.

The clinical picture of typhoid myocarditis is described with reference to three fatal cases. The disease is often overshadowed at the acme of the infection by signs of peripheral circulatory failure, escaping diagnosis during the fever period and becoming clinically manifest only during convalescence. The cardiographic diagnosis was made always during the fever period with one exception. The clinical phenomena of the myocardial damage often persist longer than the cardiographic abnormalities.

The author is indebted to Dr. M. Krause for taking the majority of the tracings.

\section{REFERENCES}

Baugé, C. (1933). Troubles du Myocarde dans les Anémies, Paris, 1933.

Bloch, C. (1937). Act. med. Scand., 93, 543.

Bowe, G. R. (1929). Canad. med. Ass. J., 20, 606.

Chagras, A. (1931). C. R. Soc. Biol., Paris, 106, 505

Clagett, A. H. (1944). Amer. J. med. Sci., 208, 811.

Delius, L. V. and Opitz, E. (1935). Dtsch. Arch. klin. Med., 178, 1. 
Dietrich, A. (1918). Z Zbl. Allgem. Pathol., 29, 169.

and Siegmund, N. (1936). Handb. Pathol. Anat., Vol. VIII, 951.

Dustin, C., Weyler, H., and Roberts, C. P. (1939). New. Engl. J. Med., 220, 13.

Feil, M. (1936). Amer. Heart J., 6, 27.

Goodof, F. F., and Macbryde, C. M. (1944). J. Clin. Endocrinol., 4, 30.

Hayem, H. (1969). Arch. Phys. Norm. Pathol., 2, 669.

Kiss, B., and Wolleck, B. (1935). Arch. Kinderheilk., 106, 38.

Knies, P. T. (1941). Amer. Heart J., 22, 804.

Landouzy, A., and Siredey (1887). Rev. Médecine, 804.

Lessard, R. (1933). Le Cour dans la Fièvre Typhoide, Paris, 1933.

Mainzer, F., and Krause, M. (1940). Brit. Heart J., 2, 85.

Master, A. M., Romanoff, A., and Jaffé, H. (1931). Proc. Soc. exp. Biol., N.Y., 6, 696.

Meier, M. S. (1940). Z. klin. Med., 138, 130.

Porter, W. B., and Bloom, N. (1935). Amer. Heart J., 10, 793.

Romberg, E. v., and Paessler, H. (1899). Dtsch. Arch. klin. Med., 64, 652. (1893). Ibid., 48, 368; 49, 412.

Scherf, D., and Klotz, S. D. (1944). Ann. intern. Med., 20, 438.

Schott, A. (1944). $\quad$ Brit. Heart J., 6, 27.

Szekely, P. (1940). Ibid., 2, 1.

Vesell, H., and Bierman, W. (1936). Amer. J. med. Sci., 191, 484.

Weiss, S., and Wilkins, R. M. (1937). Ann. intern. Med., 11, 104. 